\title{
SOURCE DISTANCE HAS NO EFFECT ON LOAD SIZE IN THE LEAF-CUTTING ANT, ATTA CEPHALOTES
}

\author{
By JAMES K. WeTtERER \\ Museum of Comparative Zoology, \\ Harvard University, Cambridge MA 02138
}

In leaf-cutting ants (Tribe Attini: Atta spp. and Acromyrmex spp.), foraging workers cut and collect plant material which they carry back to the nest. Within the nest, other workers prepare the retrieved material as a substrate for growing a specialized type of fungus that the ants use for food (Weber, 1972; Wilson, 1980a, b). Recently, Roces (1990) examined load size determination by the leaf-cutting ant, Acromyrmex lundi. He reported that workers from a laboratory colony cut different size fragments when cutting pieces of parafilm laid out at different distances from their nest. For ants of a given size, fragments cut at one meter from the nest were less than half the area of fragments cut at five meters distance.

Roces' (1990) result appears to conflict with my previous finding on the cutting behavior of a different species of leaf-cutting ant, Atta cephalotes (Wetterer, 1990). In my field experiment, I found that Atta cephalotes workers did not alter their pattern of load size determination with distance when cutting grapefruit (Citrus paradisi) leaves located six, twenty and fifty meters from the ants' nest entrance. This "negative" result agreed with the prediction of a theoretical foraging model: for Atta cephalotes workers cutting leaf fragments, the load size which maximizes return per unit foraging time (cutting time plus travel time) should not change with foraging distance (see analyses and discussion in Wetterer, 1989, 1990). To determine whether my empirical result was an artifact of the limited range of source distances examined in my original study, I repeated the experiment, this time comparing load size for Atta cephalotes workers cutting leaves at two much more extreme distances: less than one meter versus one hundred meters from their nest entrance.

Manuscript received 6 January 1992. 
I conducted this study in January 1991 at La Selva Biological Station of the Organization for Tropical Studies, Heredia Province, Costa Rica. I studied ants from one main foraging trail of a large colony of Atta cephalotes located in the station arboretum. At the time of the study, the ants on this trail were cutting leaves at several sources, including one located more than $120 \mathrm{~m}$ from the nest entrance.

I measured load size for ants cutting leaves at two artificial trees consisting of a roughened 0.5-m PVC tube with branches of thirty mature grapefruit leaves (Citrus paradisi) placed in a vial of water at the top, following procedures described earlier (Wetterer, 1990). One artificial tree was located $10 \mathrm{~cm}$ from the nest entrance, the other at a distance of $100 \mathrm{~m}$ along the same trail. I collected fifty laden ants coming down the artificial trees at each of the two distances. I measured fresh mass of each ant and leaf fragment to the nearest $0.1 \mathrm{mg}$. I then measured the area of each leaf fragment using a Licor area meter, taking the mean of three measurements. I performed statistical analyses on log-transformed data using the SAS computer statistics package (SAS Institute, 1985).

As in my earlier study (Wetterer, 1990), I found no significant effect of source distance on any factor: ant mass $(t=0.7, P=0.48$, $\mathrm{df}=1)$, fragment mass $(t=0.8, P=0.40, \mathrm{df}=1)$, fragment area $(t=0.4, P=0.70, \mathrm{df}=1)$. I also found no significant effect of source distance on the relationship between ant mass and fragment mass $(F=0.9, P=0.35, d f=1,97)$, nor on the relationship between ant mass and fragment area $(F=0.3, P=0.59, d f=1,97$, see Figure 1).

After completing the above experiment, I attempted to determine the distance from the nest entrance used in the study to the nearest fungus garden. I dug along the ants' underground tunnel for more than 1.5 meters from the entrance without finding a garden before I was finally turned back by hard soil and the bites of hundreds of soldier ants.

The results of the present study confirm and extend my previous finding that Atta cephalotes foragers do not alter their pattern of leaf cutting at different distances from their nest (Wetterer, 1990), but contrast with Roces' (1990) finding with Acromyrmex lundi. There are several possible explanations for this observed 


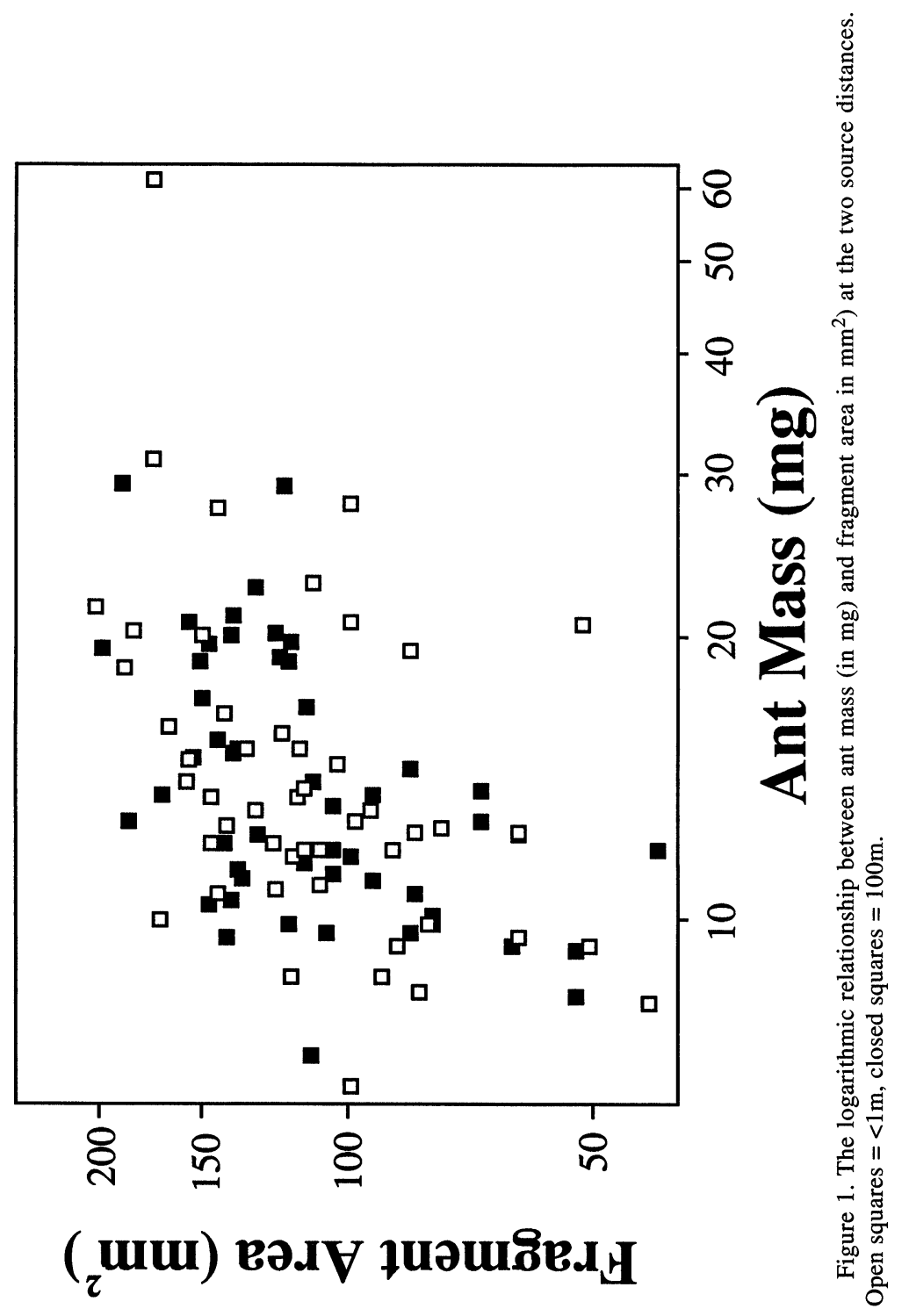


difference. One possibility is that the difference may be related to interspecific or intergeneric differences in foraging behavior. Many differences in the ecology and behavior of the various species of leaf-cutting ants have been noted in earlier studies (see Weber, 1972; Wetterer, 1992). A second possibility is that the difference is due to some difference in experimental procedure. For example, Roces (1990) examined ants cutting parafilm lying flat on the ground in the laboratory, whereas I examined ants cutting leaves suspended from branches.

A third possibility is that both species of leaf-cutting ant have more than one mode of leaf cutting, but that my experiments examined conditions only appropriate for one of the modes. Specifically, leaf-cutting ants may have two different modes of cutting that correspond to two steps in the process of acquiring and preparing vegetable matter for their fungus garden (see Wilson, 1980a). At outside leaf sources, workers cut large leaf fragments appropriate for efficient transport back to the nest. Inside the nest, workers then cut small pieces from these retrieved fragments as they prepare the leaf material for incorporation into the fungus garden. In my experiment, both artificial trees were treated as outside leaf sources. In Roces' (1990) laboratory experiment, however, the Acromyrmex lundi workers may have treated parafilm located one meter from their fungus garden as if it were located inside the nest because, under natural conditions, vegetation found that close to the garden generally has been left there by other workers. In other words, the difference in cutting behavior Roces (1990) observed in Acromyrmex lundi workers cutting parafilm at different distances from their fungus garden may be related to two different steps in the foraging process: 1) transporting leaf material back to the nest (large fragments at five meters) and 2) degrading (sensu Wilson, 1980a) retrieved material (small pieces at one meter). Laboratory studies of Atta cephalotes cutting parafilm and field studies of Acromyrmex lundi cutting leaves may easily test this proposal.

\section{ACKNOWLEDGEMENTS}

I thank M. Wetterer and K. Harms for comments on this manuscript. Financial support was provided by the Organization for Tropical Studies, the Jesse Smith Noyes Foundation, the American Philosophical Society, and the National Science Foundation 
(grants BSR 8906869 to S. Hubbell and BSR 9103782 to J. Wetterer).

\section{Literature CITED}

ROCES, E.

1990. Leaf-cutting ants cut fragment sizes in relation to distance from the nest. Animal Behaviour 40: 1181-1183.

SAS InSTITUTE

1985. SAS User's Guide: Statistics, Version 5 Edition. Cary NC: SAS Institute.

WEBER, N. A.

1972. Gardening ants: the attines. American Philosophical Society. Philadelphia, PA.

WetTERER, J. K.

1989. Central place foraging theory: when load size affects travel time. Theoretical Population Biology 36: 267-280.

1990. Load-size determination in leaf-cutting ants. Behavioral Ecology 1: 95101.

1991. Foraging ecology of the leaf-cutting ant Acromyrmex octospinosus in a Costa Rican rain forest. Psyche 98(4): 361-371.

Wilson, E. O.

1980a. Caste and division of labor in leaf-cutter ants. I. The overall pattern in A. sexdens. Behavioral Ecology and Sociobiology 7: 143-156.

1980b. Caste and division of labor in leaf-cutter ants. II. The ergonomic organization of leaf cutting. Behavioral Ecology and Sociobiology 7: 157-165. 

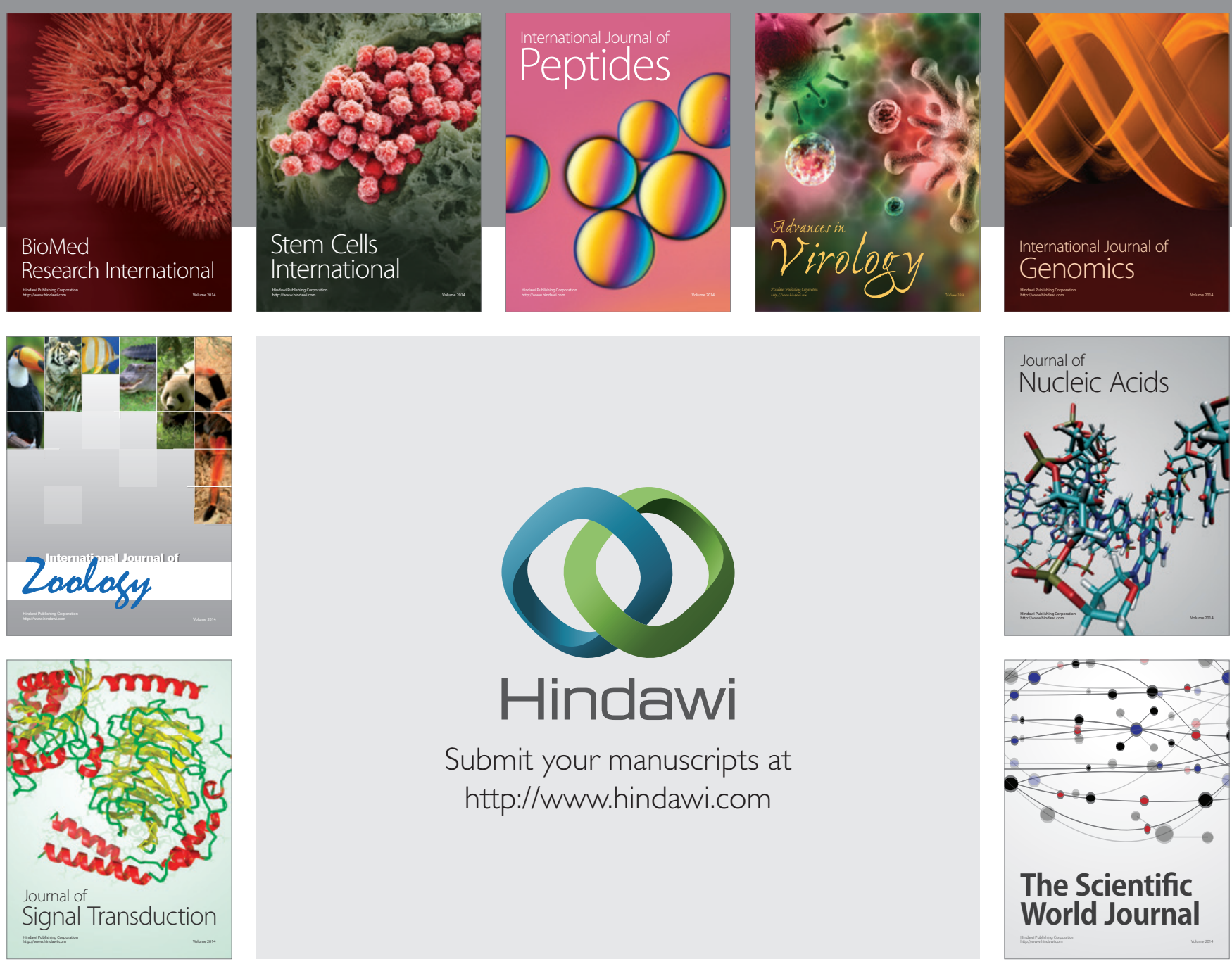

Submit your manuscripts at

http://www.hindawi.com
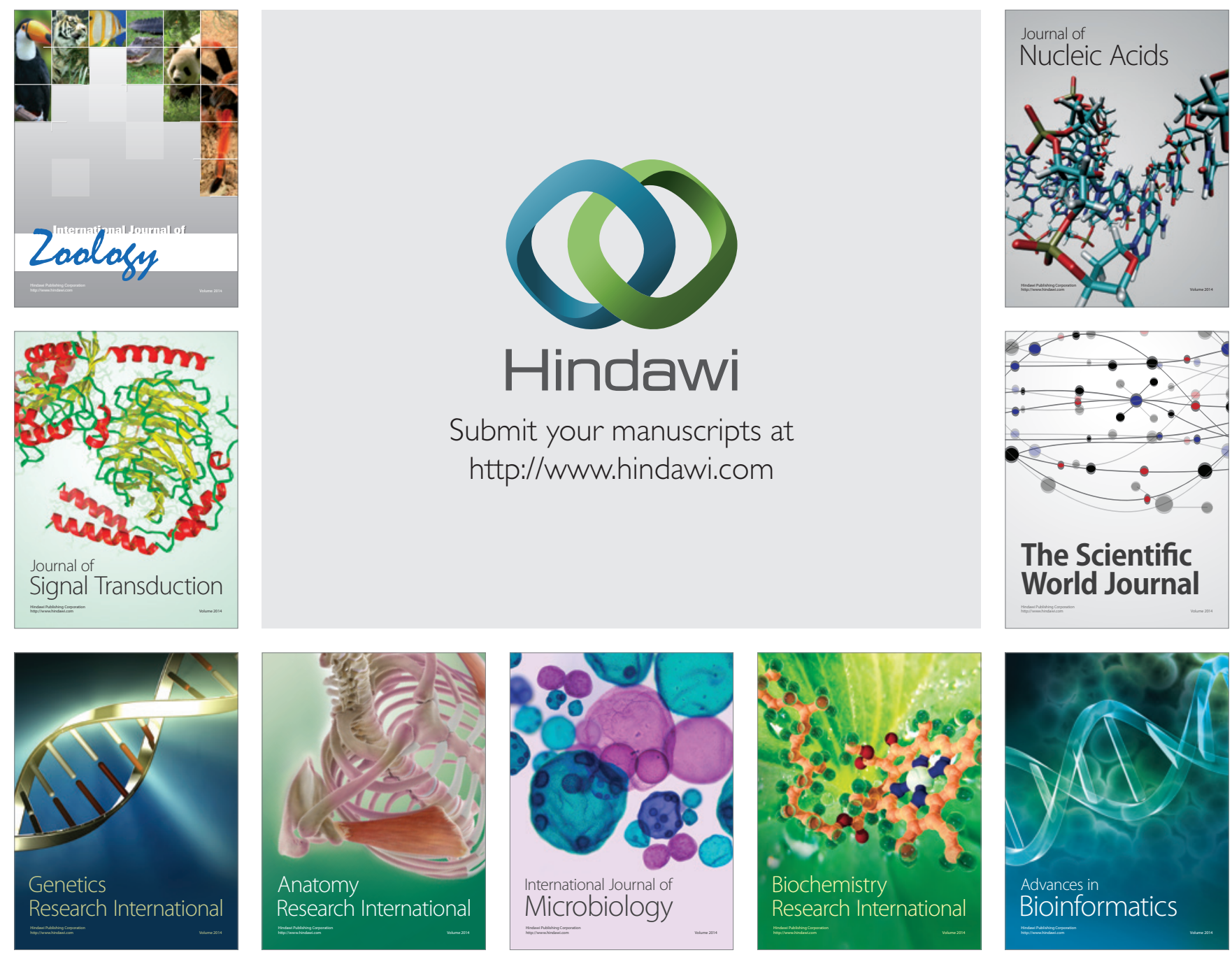

The Scientific World Journal
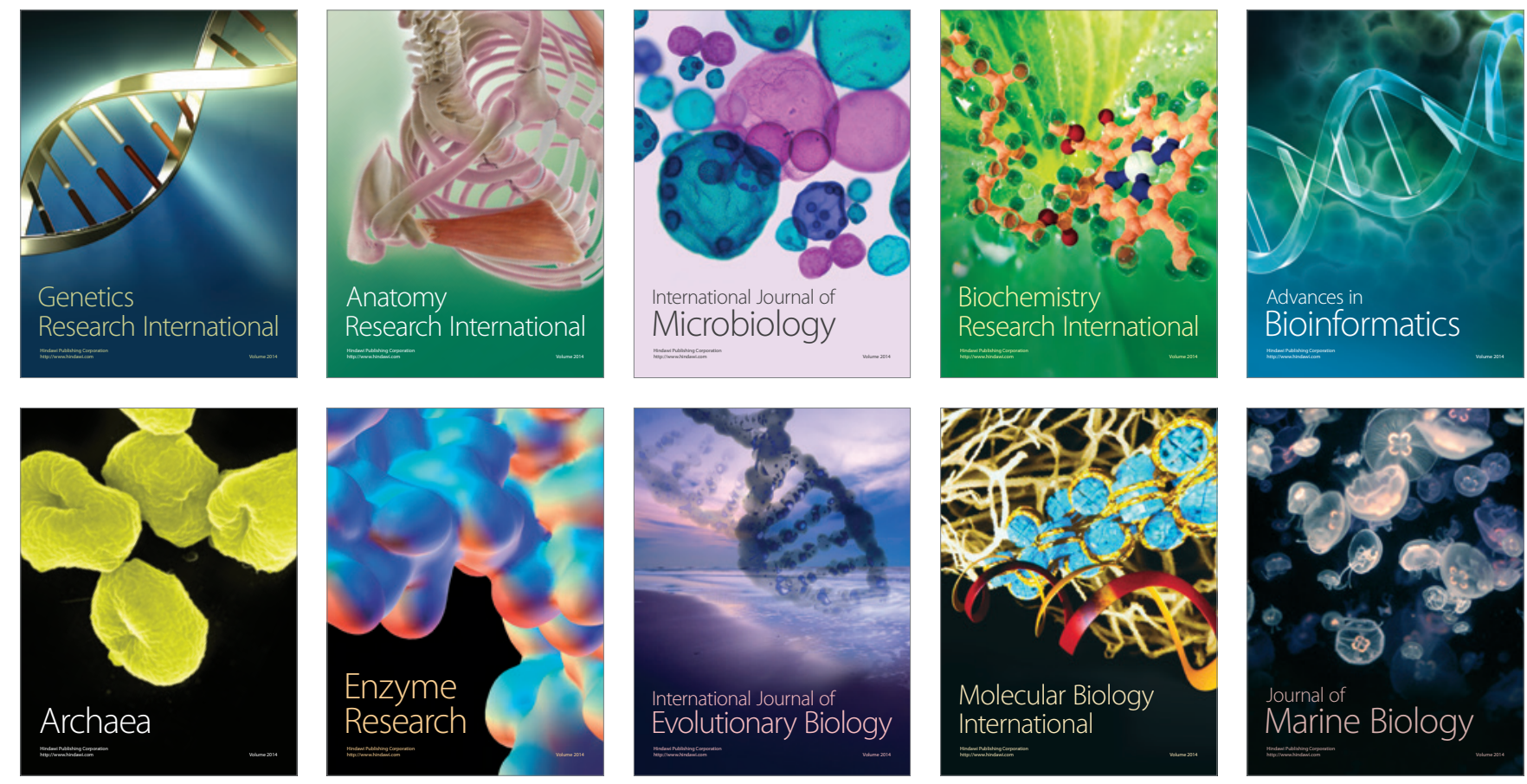